\section{LA CALIDAD DEL HÁBITAT PARA LA VIVIENDA DE INTERÉS SOCIAL. SOLUCIONES DESARROLLADAS ENTRE 2000 Y 2007 EN BOGOTÁ}

Alex Leandro Pérez Pérez²

\section{Resumen}

En respuesta a una convocatoria lanzada por la Comisión Permanente de Calidad del Hábitat de la Sociedad Colombiana de Arquitectos en 2007, un equipo multidisciplinario presentó una propuesta de proyecto de investigación que fue aprobado y cuyos resultados para Bogotá se comentan y resumen en el presente artículo.

A partir de una muestra seleccionada de 124 soluciones habitacionales de vivienda de interés social construidas en Bogotá durante el período 2000-2007, se aplicó un instrumento diseñado para recoger información encaminada a evaluar su calidad sobre la base de la satisfacción de las necesidades de los usuarios. El procesamiento de los resultados ha permitido caracterizar el objeto de

\section{QUALITY OF HABITAT FOR SOCIAL HOUSING. SOLUTIONS DEVELOPED BETWEEN 2000 AND 2007 IN BOGOTÁ'}

Alex Leandro Pérez Pérez ${ }^{2}$

\section{Abstract}

In response to a call for proposals launched by the Colombian Society of Architects' Permanent Commission for Habitat Quality in 2007, a multidisciplinary team submitted a research project that was approved; the results of this study are commented and summarized on this paper.

An instrument designed to assess the quality of housing based on users' satisfaction was applied to a sample of 124 social housing units built between 2000-2007. The results have enabled the characterization of the subject of study (housing, environment and users) and the assessment of its integral quality. As a result, professionals' responsibility 
estudio (viviendas, entorno y usuarios) y evaluar su calidad integral, precisando la responsabilidad de los profesionales con los usuarios y la participación de los beneficiarios en la producción y transformación de su hábitat.

Se demuestra que los proyectos se caracterizan por una pobre imagen estética, no responden adecuadamente a las necesidades básicas del usuario y no ofrecen alternativas flexibles en procesos participativos. Por el contrario, generan segregación socio-espacial y no benefician a los sectores más vulnerables, sino a la inversión de capital sin un mejoramiento significativo de la calidad de vida.

\section{PALABRAS CLAVES: CALIDAD DEL HÁBITAT; V.I.S FORMAL EN BOGOTÁ; SATISFACCIÓN DE LAS NECESIDADES HABITACIONALES.}

Fecha de recepción: 23.12.10

Fecha de aceptación: 10.06.11

1 El trabajo es producto de la investigación “Diagnóstico preliminar de la calidad del hábitat en proyectos VIS (2000-2007) en Colombia, hacia un manifiesto nacional de calidad del hábitat", realizada entre julio de 2007 y agosto de 2009, patrocinada por la Universidad de La Salle, Facultad de Ciencias del Hábitat, Bogotá-Colombia, ULS, el Consejo Profesional Nacional de Arquitectura y sus profesiones Auxiliares CNPAA, y la Sociedad Colombiana de Arquitectos, Comisión Permanente para la Calidad del Hábitat SCA - CPCH.

2 Colombia. Arquitecto, Máster en Ciencias y aspirante a Doctor en Arquitectura. Especialista en vivienda con estudios y trabajos en gestión, diseño, construccióny planificación urbana. Docente einvestigador de la Facultad de Ciencias del Hábitat de la Universidad de La Salle, Bogotá-Colombia. Email: aleperez@unisalle.edu.co to users has been determined as well as beneficiaries' participation in the production and transformation of their habitat.

The paper shows that projects are characterized by a poor aesthetic image; likewise, these initiatives do not properly meet users' basic needs and do not offer flexible alternatives within participatory processes. On the contrary, these projects generate socio-spatial segregation and prioritize capital investment, disregarding the most vulnerable groups; as a consequence, there is no significant improvement in quality of life.

\section{KEY WORDS: QUALITY OF HABITAT; FORMAL SOCIAL HOUSING IN BOGOTÁ, HOUSING NEEDS SATISFACTION}

Received: 23.12.10

Accepted: 10.06.11

1 This paper is part of the research "Preliminary Diagnosis of Housing Quality in SC projects (2000-2007) in Colombia, towards a National Manifesto on Housing Quality" carried out between July, 2007 and August, 2009 and sponsored by the School of Habitat Sciences, La Salle University; the National Professional Council of Architecture and Auxiliary Professions, CNPAA; and the Colombian Society of Architects' Permanent Commission for Habitat Quality, SCA-CPCH.

2 Colombia. Architect, MA in Sciences, Ph.D. Candidate in Architecture. Specialist in housing with research and studies in management, design, construction and urban planning. Academic and researcher, School of Habitat Sciences, La Salle University, Bogotá, Colombia. email: aleperez@unisalle.edu.co 


\section{Introducción}

En julio de 2007 la Comisión Permanente de Calidad del Hábitat de la Sociedad Colombiana de Arquitectos (SCA) ${ }^{3}$ lanzó una convocatoria para realizar un diagnóstico preliminar sobre la calidad de la Vivienda de Interés Social (VIS ${ }^{4}$ ) en Colombia en el período 2000-2007. Un equipo multidisciplinario de profesores e investigadores presentó una propuesta de proyecto de investigación que fue aprobado y cuyos resultados para Bogotá se comentan y resumen en el presente artículo.

La importancia del trabajo radica en que se evalúa desde una perspectiva crítica la calidad de la vivienda formal, su contexto y relación con la ciudad para los sectores de bajos ingresos, y se detecta la falta de una respuesta adecuada a la producción de hábitat por parte de arquitectos y urbanistas a partir de las posturas asumidas en su actividad profesional.

3 La Comisión Permanente de Calidad de Hábitat (CCH) es una instancia de la SCA Presidencia Nacional, en la cual tienen asiento la Asociación Colombiana de Facultades de Arquitectura y el Consejo Profesional Nacional de Arquitectura y sus Profesiones Auxiliares. La Comisión canaliza los proyectos e iniciativas que, en materia de hábitat, aborda la SCA Presidencia Nacional.

4 Para los objetivos de la investigación, esta se refiere a vivienda de interés social, al aludir aquella solución habitacional que ha sido ofertada y construida por empresas inmobiliarias, adquirida con algún tipo de subsidio por intermedio de entes facilitadores y en cumplimiento de elegibilidad dispuesto por la Ley 3 de 1991 y Decreto 975 de 2004, en desarrollo formal y ofrecida legalmente por la oferta del mercado inmobiliario.
La vivienda, particularmente la de interés social, constituye uno de los ejes más importantes en la planificación de la ciudad. En este sentido, los resultados que se presentan aportan a la construcción del conocimiento y la discusión teórica sobre los retos a enfrentar desde una postura profesional apropiada para la construcción de una sociedad más justa y equitativa.

\section{Metodología}

Analizar las características de la vivienda y su calidad implica una interacción compleja entre muchas dimensiones. El objetivo de construir un hábitat educativo ${ }^{5}$ para la sociedad y en especial para los más vulnerables se encuentra plasmado en documentos ampliamente difundidos ${ }^{6}$, que abogan por el logro de ciudades sustentables, donde la solución habitacional se inserta y articula estratégicamente.

5 Que permita una sociedad equitativa que disminuya la brecha entre ricos y pobres; justa, que favorezca el acercamiento entre los diferentes actores (el Estado y los sectores públicos y privados) para lograr mitigar el impacto de las acciones humanas en la naturaleza. Así se genera una cultura ciudadana sobre principios de respeto mutuo, solidaridad y participación.

6 El Derecho Humano a la vivienda Adecuada (1993), Las bases del Plan de Acción Regional de América Latina y El Caribe sobre Asentamientos Humanos (2001) aprobados en la Conferencia Estambul más 5 y la Carta Mundial por el Derecho a la Ciudad (2003, 2004, 2005). 
Dentro de las metodologías propuestas para identificar la población vulnerable y considerar el nivel de calidad de las soluciones habitacionales, se destacan los indicadores de Necesidades Básicas Insatisfechas (NBI), propuestos por la CEPAL en la década de los '70, difundidos luego por toda Latinoamérica y aplicados posteriormente en Colombia desde el año 1987 hasta la actualidad (DANE, 2005).

El Índice de Necesidades Básicas Insatisfechas (NBI) identifica cinco situaciones relacionadas con la calidad para las condiciones físicas de la vivienda, el acceso a los servicios públicos básicos, el hacinamiento en la vivienda, el acceso a la educación y la dependencia económica (Encuesta Calidad de Vida Bogotá, ECVB, 2007).

La rigidez del método estadístico y el uso de componentes estandarizados simplifican la definición y evaluación de las condiciones que generan la pobreza, así como las deficiencias en la calidad habitacional, confirmando entonces la necesidad de nuevas alternativas para su evaluación. Los modelos de evaluación de la calidad del hábitat deben constituir representaciones de la realidad, prever y conocer el funcionamiento de la vivienda y su entorno, para luego permitir la formulación de alternativas encaminadas al mejoramiento de la condición resultante y nuevamente su evaluación.
Contrario al enfoque de las Necesidades Básicas Insatisfechas, que hace énfasis en las carencias, el enfoque del Desarrollo Humano impulsado por el PNUD desde 1990 representa una visión más comprensiva de la realidad. Esto significa trasladar la "medida del éxito" desde la mera evaluación del desempeño económico hacia la forma en que ese desempeño se traduce en mayores oportunidades, mostrando la acumulación de capacidades humanas y la inclusión de múltiples dimensiones (PNUD, 2000 al 2009).

Diversos autores han incorporado a la problemática habitacional para los sectores de bajos ingresos económicos conceptos y categorías como "la calidad," "calidad de vida", "habitabilidad" y "satisfacción residencial", que incluyen al usuario en la evaluación de las necesidades a satisfacer por la vivienda, así como la relación con su entorno (De la Puente, P., Muñoz, P., Torres, E., 1990), (Gonzalez C., D., 1997), (Hidalgo, R., 1998). (Tarchópulos, D., Ceballos, O., 2003), (Saldarriaga R., A., 2003), (Leva, G., 2005). También algunos países de la región ya incorporan en sus políticas de vivienda el concepto de la calidad de vida, como es el caso de Bolivia (Jiménez C., S., Terceros O., R., 2009) y Chile $^{7}$ los cuales coinciden con los objetivos incluidos en la Carta Mundial por el Derecho a la Ciu-

$7 \quad$ Análisis de los resultados del Seminario Internacional para el desarrollo de las Políticas de Vivienda celebrado en La Paz en octubre de 2009 (sin publicar). 
dad (Foro Social Mundial de Porto Alegre 2003, Foro Social de las Américas realizado en Quito 2004, Foro Mundial Urbano en Barcelona 2004, Foro Social Mundial en Porto Alegre, Enero 2005).

Para el continuo mejoramiento de la calidad de vida de la población beneficiada, lo cual debe ser favorecido por la visión y oferta de la práctica profesional, se considera fundamental hacer énfasis en la satisfacción de las necesidades habitacionales de los sectores de bajos ingresos sobre principios de justicia, equidad y democracia en la transformación del medio ambiente construido.

Para el desarrollo de la investigación sobre la calidad del hábitat en las urbanizaciones de vivienda de interés social en Bogotá, se elaboró un modelo teórico a partir del cual se identifican las variables objeto de estudio y la interrelación entre ellas (Perez, 2008). Se entendió así la calidad de la vivienda como su aptitud para ser habitada con satisfacción por sus ocupantes. Por tanto, los dos grupos de variables que se interrelacionan son los usuarios (individuos y familias) y el hábitat (la vivienda y su contexto).

Las necesidades y expectativas de los usuarios se han ordenado en una línea de tiempo que va del pasado al futuro, reforzando el carácter del mejoramiento continuo de la vivienda y la satisfacción de las necesidades cambiantes, a lo cual el diseño deberá dar respuesta (Figura 1). Por otra parte, el hábitat se analiza en tres escalas que corresponden a la evaluación de la vivienda misma a escala arquitectónica, en relación con su entorno inmediato y con la ciudad donde se inserta (Figura 2).

A partir de esta construcción teórica y metodológica se definieron las variables de cada grupo, los parámetros a través de los cuales estas se manifestaban y los indicadores requeridos en su evaluación, todo lo cual sirvió de base para elaborar los instrumentos de recolección de la información con vistas al diagnóstico.

El esquema de la Figura 3 resume la forma de caracterizar al usuario para poder interpretar sus criterios sobre la satisfacción de necesidades y expectativas. El individuo y la familia corresponden a la escala de la vivienda. Estos a su vez se relacionan con la comunidad de vecinos en el entorno urbano y luego con todos los habitantes de la ciudad.

Las variables que proporcionan la satisfacción de las necesidades humanas en el contexto urbano deben considerar, por un lado, la provisión de ciertas cantidades y calidades de bienes y servicios, y por otro, la percepción subjetiva ligada a la accesibilidad a dichos beneficios urbanos e integración a ellos. Las variables, los parámetros e indicadores consultados en las tres escalas de análisis se exponen en las Tablas 1 y 2.

La información recopilada en el trabajo de campo a través del empleo de los instrumentos elaborados provino de dos fuentes: la observación directa y 
FIGURA 1. ENFOQUE DE RELACIONES PARA LA EVALUACIÓN SEGÚN EL PASADO / PRESENTE / FUTURO.

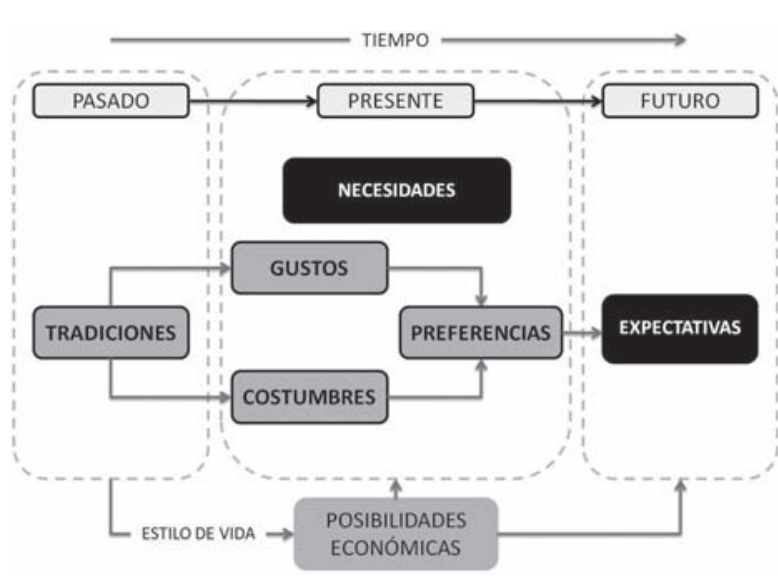

FUENTE: Diagrama de análisis del autor

\section{FIGURA 3. CARACTERIZACIÓN DEL USUARIO Y LA FAMILIA EN LA VIVIENDA Y SU ENTORNO.}

FUENTE: Diagrama de análisis del autor.
FIGURA 2. GRUPOS DE ANÁLISIS PARA LA VALORACIÓN DEL HÁBITAT URBANO.

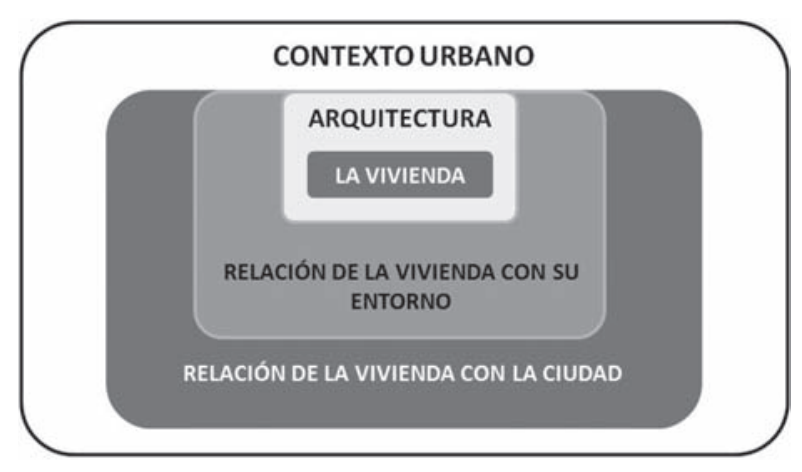

FUENTE: Diagrama de análisis del autor.

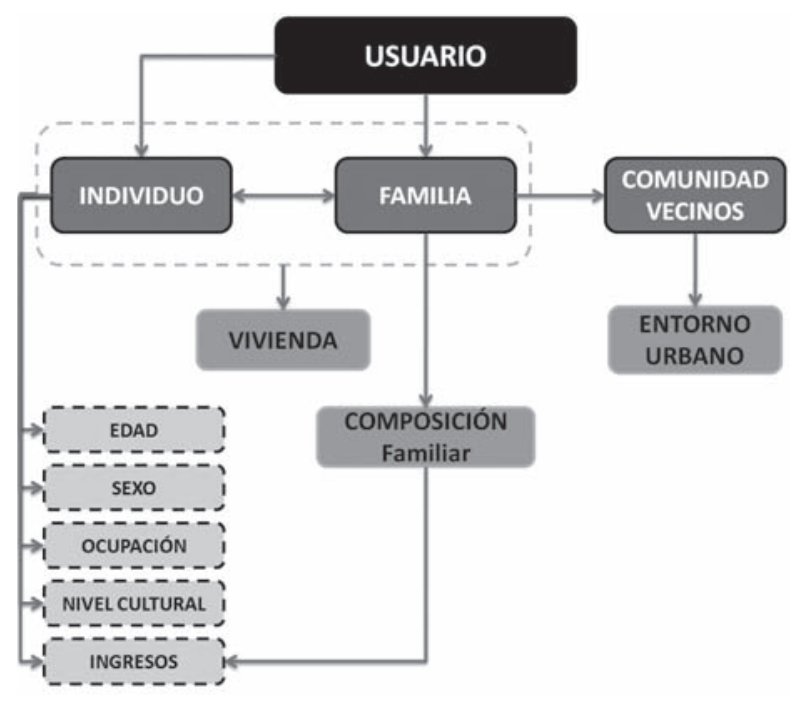

ARTíCULO: La calidad del hábitat para la vivienda de interés social. Soluciones desarrolladas entre el 2000 y el 2007 en Bogotá / Alex Leandro Pérez Pérez 
TABLA 1. VARIABLES IDENTIFICADAS. LA RELACIÓN DE LA VIVIENDA CON LA CIUDAD Y SU VINCULACIÓN CON EL ENTORNO. PARÁMETROS E INDICADORES.

\begin{tabular}{|c|c|c|c|}
\hline VARIABLE & SUBVARIABLE & PARÁMETRO & INDICADOR \\
\hline \multirow{9}{*}{ 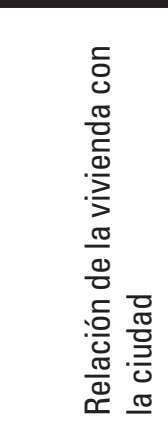 } & \multirow{9}{*}{ 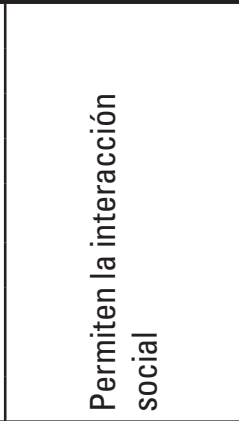 } & \multirow{3}{*}{$\begin{array}{l}\text { Relación de la vivienda con la centrali- } \\
\text { dad física de la ciudad }\end{array}$} & Distancia \\
\hline & & & Medio de transporte \\
\hline & & & Tiempo \\
\hline & & \multirow{3}{*}{ Relación vivienda trabajo } & Distancia \\
\hline & & & Medio de transporte \\
\hline & & & Tiempo \\
\hline & & \multirow{3}{*}{ Relación vivienda servicios } & Distancia \\
\hline & & & Medio de transporte \\
\hline & & & Tiempo \\
\hline \multirow{11}{*}{ 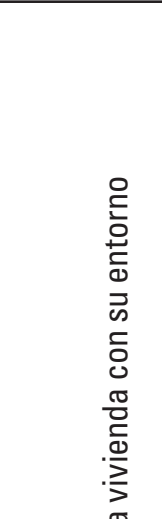 } & \multirow{10}{*}{ 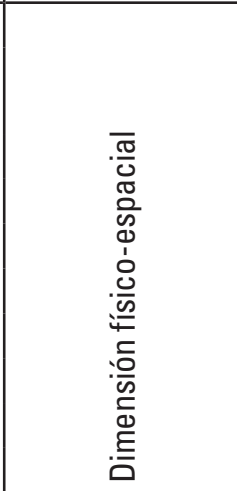 } & \multirow{5}{*}{$\begin{array}{l}\text { Morfología } \\
\text { Tipología }\end{array}$} & Relación llenos y vacíos \\
\hline & & & $\begin{array}{l}\text { Distribución de áreas publicas comunes } \\
\text { y privadas }\end{array}$ \\
\hline & & & Número de pisos \\
\hline & & & Variedad de la oferta habitacional \\
\hline & & & Densidad \\
\hline & & \multirow{3}{*}{ Infraestructura } & Infraestructura de movilidady transporte \\
\hline & & & Vías \\
\hline & & & Servicios públicos domiciliarios \\
\hline & & \multirow{2}{*}{$\begin{array}{l}\text { Equipamientos } \\
\text { comunitarios }\end{array}$} & Espacios para el intercambio \\
\hline & & & Espacios para la manifestación \\
\hline & \multirow{4}{*}{$\begin{array}{l}\text { Dimensión } \\
\text { físico-ambiental }\end{array}$} & \multirow{2}{*}{ Espacios verdes } & Preparación de espacios verdes \\
\hline \multirow{3}{*}{$\begin{array}{l}\frac{\overline{0}}{0} \\
\frac{0}{0} \\
\frac{1}{0} \\
\frac{0}{0} \\
\frac{\pi}{0} \\
\frac{1}{0}\end{array}$} & & & Apropiación del espacio publico \\
\hline & & \multirow{2}{*}{$\begin{array}{l}\text { Vulnerabilidad } \\
\text { física }\end{array}$} & inundaciones \\
\hline & & & Deslizamientos y derrumbes \\
\hline
\end{tabular}

FUENTE: Elaboración del autor. 
TABLA 2. VARIABLES IDENTIFICADAS. EL ESPACIO HABITABLE (LA VIVIENDA). PARÁMETROS E INDICADORES.

\begin{tabular}{|c|c|c|c|}
\hline VARIABLE & SUBVARIABLE & PARÁMETRO & INDICADOR \\
\hline \multirow{24}{*}{$\begin{array}{l}\frac{0}{0} \\
\frac{\pi}{0} \\
\frac{\pi}{0} \\
\frac{\sigma}{\pi} \\
\frac{0}{0} \\
\frac{0}{0} \\
\frac{0}{0} \\
\frac{0}{4}\end{array}$} & \multirow{13}{*}{ 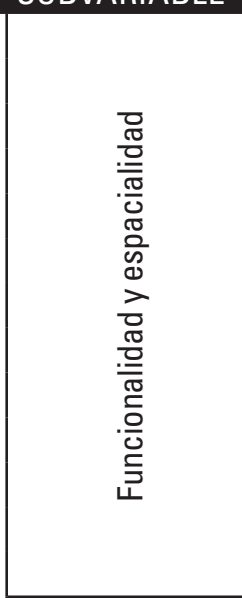 } & \multirow{7}{*}{ Espacio } & Cantidad \\
\hline & & & Usos \\
\hline & & & Dimensionesy equipamiento \\
\hline & & & Transformaciones \\
\hline & & & Relaciones \\
\hline & & & Higiene y limpieza \\
\hline & & & Productividad \\
\hline & & \multirow{3}{*}{ Confort } & Térmico \\
\hline & & & Lumínico \\
\hline & & & Acústico \\
\hline & & \multirow{3}{*}{ Forma (Volumen) } & Tipología \\
\hline & & & Número de pisos \\
\hline & & & Lote (Dimensiones y disposición) \\
\hline & \multirow{11}{*}{ 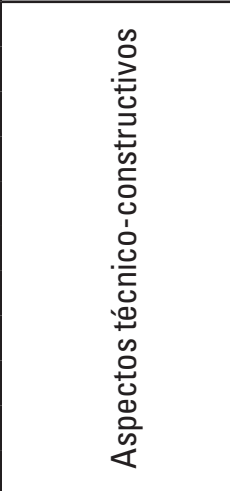 } & \multirow{5}{*}{ Adaptabilidad } & Integración al conjunto \\
\hline & & & \begin{tabular}{|l|} 
Rasgos distintivos (transformación) \\
\end{tabular} \\
\hline & & & Aportes positivos \\
\hline & & & Flexibilidad \\
\hline & & & Accesibilidad universal \\
\hline & & \multirow{6}{*}{ Materiales y tecnologías } & Sistema estructural \\
\hline & & & Instalaciones \\
\hline & & & Fachada \\
\hline & & & Carpintería y protección solar \\
\hline & & & Cubierta \\
\hline & & & Terminaciones \\
\hline
\end{tabular}

FUENTE: Elaboración del autor. 
objetiva del profesional sobre las características de la vivienda y su contexto, y la opinión del usuario sobre su grado de satisfacción, con su correspondiente carga subjetiva.

Las preguntas elaboradas para recopilar la información de cada indicador permiten la caracterización de las variables, y por medio de su relación en el tiempo (pasado, presente y futuro) se valora la calidad de las soluciones según los aspectos que favorecen o no la satisfacción en los usuarios consultados.

Con la información recopilada en el trabajo de campo se construyó una base de datos que contiene, además de las fichas de inventario por urbanización y las encuestas por vivienda, mapas, planos y fotos. Estos datos fueron procesados estadísticamente mediante el programa SPSS $^{8}$, para arribar a resultados que permitieran evaluar el comportamiento entre las soluciones arquitectónicas y urbanas y su calidad. Esos resultados, expresados en indicadores, fueron posteriormente sometidos a consulta de expertos con el objetivo de validar el grado de importancia de determinadas variables y parámetros en la calidad del hábitat y la satisfacción de la población.

8 Las siglas SPSS corresponden a Statistical Package for the Social Sciences, software informático usado en las ciencias sociales para el análisis de información estadística que proporciona herramientas para el análisis de encuestas y entrevistas por medio de métodos descriptivos o inferenciales.

\section{FUNDAMENTACIÓN DEL PERÍODO DE ESTUDIO}

La investigación se acotó en el período de los años 2000-2007 en virtud del desarrollo e implementación de los Planes de Ordenamiento Territorial (POT) en los municipios colombianos, los cuales se estructuraron a partir de la expedición de la ley 388 de 1997 o "de desarrollo territorial", que incorpora principios e instrumentos fundamentales, como la función social y ecológica de la propiedad, la distribución equitativa de cargas y beneficios, la función publica del urbanismo y la participación democrática de los ciudadanos en el ordenamiento territorial. Según la visión de los expertos ${ }^{9}$, esta ley constituyó un avance significativo para potenciar al urbanismo como una función pública.

Con este cambio estructural en la modernización del Estado, los promotores privados asumen una mayor responsabilidad durante el período de estudio (2000-2007), y sus propuestas habitacionales, aunque se basan en los parámetros definidos en las normas urbanas expedidas por los municipios, no necesariamente favorecen la calidad de la vivienda y el hábitat construido.

9 Se refiere a los creadores de la ley citados por el abogado Fernando Laserna Silva en el foro de Alcaldes de Cundinamarca, “Construyendo vínculos para una visión regional". Febrero 15 de 2008, Bogotá

revista invi № 72 / Agosto 2011 / Volumen № 26: 95-126 103 


\section{CARACTERIZACIÓN DEL UNIVERSO}

Dado que el propósito era evaluar la calidad del hábitat en las urbanizaciones de viviendas de interés social producidas en Bogotá del 2000 al 2007, el universo se definió a partir de los datos entregados por el Departamento Administrativo Nacional de Estadística (DANE), según los cuales el número de soluciones habitacionales realizadas en el período de estudio fue de 129.374 unidades.

Para determinar la composición detallada de esa cifra global, se asumió la información aportada por el Departamento de atención al público e investigadores del $\mathrm{DANE}^{10}$, donde se establece, con un alto grado de confiabilidad, el número de unidades de vivienda construidas por departamentos y municipios, según su tipo ${ }^{11}$.

De acuerdo con las encuestas oficiales ${ }^{12}$, las opciones utilizadas para el tipo habitacional son: la "casa"

10 Departamento Administrativo Nacional de Estadística, septiembre 2007. Investigación de registro administrativo titulada "Estadísticas de edificación, licencias de construcción", cuya última actualización ocurre en 1997 y recopila información sobre el potencial de la actividad constructiva para la vivienda en el país.

11 Se diferencia el tipo VIS y el resto se clasifica por estrato socioeconómico (en Colombia la estratificación social se basa en las remuneraciones que reciben o los impuestos que pagan las personas; el estrato más bajo es 1 y el más alto es 6 . La VIS se encuentra en los estratos 1,2 y 3 ).

12 Se refiere a las estadísticas realizadas por el Departamento Administrativo Nacional de Estadística, como por ejemplo, el censo de 2005 o la encuesta de calidad de vida Bogotá 2007, donde la vivienda se clasifica en tipos.

104 revista invi № 72 / Agosto 2011 / Volumen № 26: 95-126 (entendida como la vivienda unifamiliar) y el "apartamento", que es la alternativa en soluciones multifamiliares. Partiendo de esta clasificación se decidió utilizar un muestreo estratificado en casas y apartamentos.

La información cuantitativa disponible solo incluía los primeros cuatro meses de los años 2001, 2003, 2005 y 2007, y arrojó un total de 13.165 soluciones habitacionales VIS (casas y apartamentos) construidas en el período, de las cuales el $65 \%$ son tipo casa y el 35\% restantes apartamentos. Considerando una confianza del $95 \%$, un porcentaje de error del $4 \%$ y teniendo en cuenta la distribución por estratos, se tomó 0,65 como máxima variabilidad porcentual y se determinó un tamaño de muestra de 124, que se distribuyó proporcionalmente por estratos, según la población, aplicándose dentro de cada uno el muestreo aleatorio simple para elegir los elementos concretos que formaron parte de la muestra (Universidad de La Salle, 2009). 
Fue necesario entonces, ubicar en la ciudad las zonas urbanas donde fueron construidas viviendas de interés social en el período estudiado, con vistas a conocer la distribución espacial del universo. Para ello se consultaron los medios de prensa que dentro de la dinámica del mercado habitualmente proporcionan la oferta de soluciones habitacionales, así como a miembros en la Sociedad Colombiana de Arquitectos SCA y constructores invitados. En todos los casos se buscaba información sobre los sectores donde se concentró la actividad constructiva de la VIS durante el período 2000-2007, y también acerca de su impacto en la ciudad. Se consultó además el POT de Bogotá y sus revisiones (2004) en relación con el uso del suelo y la vivienda de interés social.

Bogotá cuenta con una distribución administrativa compuesta por 19 localidades ${ }^{13}$ que fueron contempladas en la encuesta de calidad de vida (SDP 2007), de la cual se tomaron en consideración algunas variables para la selección de la muestra: la línea de pobreza, las necesidades insatisfechas y el promedio de gastos mensuales en grandes ítems, así como en servicios públicos. Se observó que las mayores falencias en aspectos socioeconómicos

13 Corresponden a las zonas cuyas características evolutivas y de servicios fueron definidas en el proceso de organización de la ciudad, y están delimitadas con claridad por la estructura vial principal y referentes naturales de importancia para cada uno de los sectores. ocupaban más de la mitad del área de la ciudad, abarcando zonas urbanas centrales, parte del occidente y todo el sur. Por otra parte, se decidió excluir de la muestra las áreas conurbadas de municipios cercanos y ejemplos que fueron construidos en el período de estudio utilizando la norma, pero sin cumplir el fin social.

Toda esta información se tuvo en cuenta para la selección de la muestra, identificándose casos de estudio no solo en los megaproyectos de Metrovivienda ${ }^{14}$ al sur y occidente, sino también en pequeños desarrollos situados en áreas urbanas centrales y al norte de la ciudad. También se consideró la necesaria distribución por estratos para la selección final de la muestra, constituida por 124 unidades habitacionales estratificadas en 43 casas y 81 apartamentos distribuidos en toda la ciudad.

Los puntos de mayor concentración de vivienda de interés social son las áreas urbanas del occidente y el sur de la ciudad, ya que más del 70\% de las viviendas se concentran en estas zonas, mientras que a las áreas urbanas centrales corresponde solo el 5\% de la muestra y a las áreas al norte de la ciudad el 20\%.

14 Metrovivienda es una empresa industrial y comercial de la Alcaldía Mayor de Bogotá, que se dedica a la generación de suelo urbanizado para desarrollar proyectos de vivienda de interés social en la ciudad.

revista invi № 72 / Agosto 2011 / Volumen № 26: 95-126 105 
FIGURA4. UBICACIÓN DE LA MUESTRA EN LA CIUDAD.

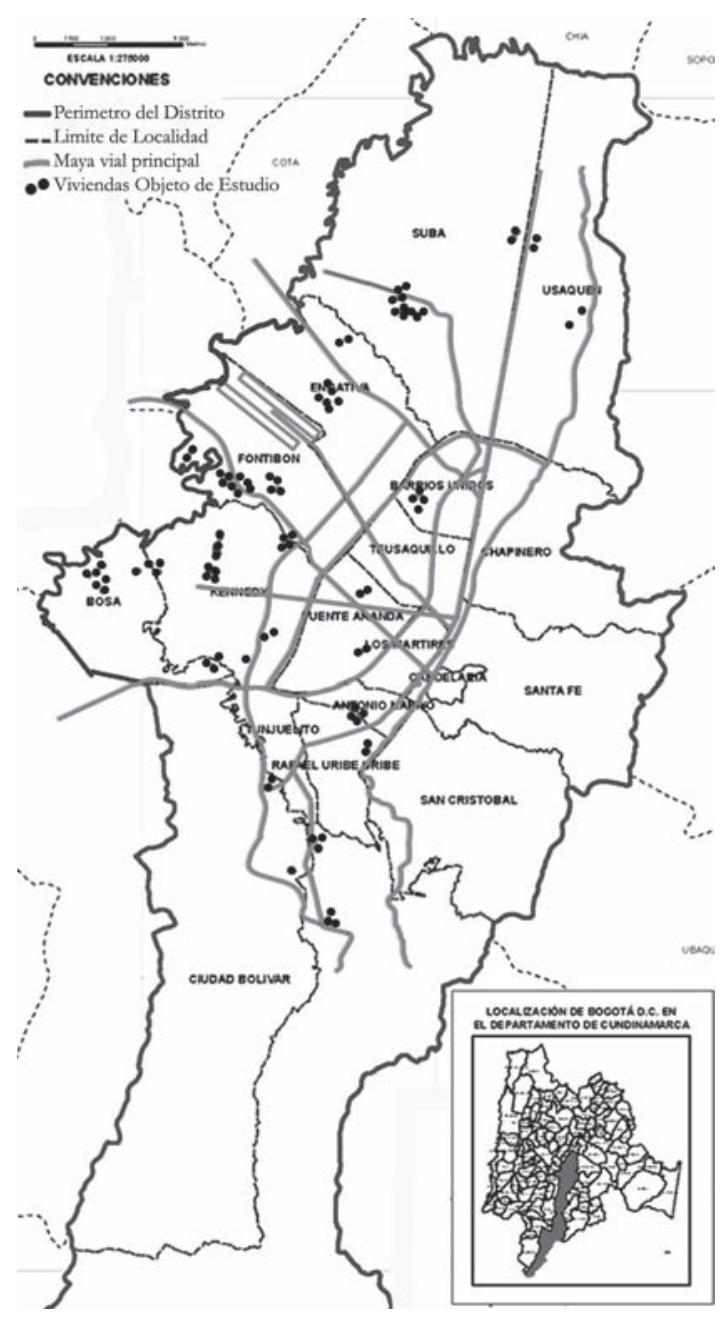

FUENTE: Elaboración propia del autor.

\section{INSTRUMENTO PARA LA RECOLECCIÓN DE INFORMACIÓN EN EL TRABAJO DE CAMPO}

Para dar respuesta a la solicitud de la Comisión de Calidad del Hábitat de la SCA fue creado un instrumento que sería aplicado en todo el país por equipos de profesionales, cada uno con un coordinador. Entonces, se diseñó una colección de fichas acompañadas de las guías de referencia conceptual y procedimental necesarias para la recopilación de la información, una para el coordinador y otras dos para los encuestadores.

Ese instrumento fue puesto a prueba por un equipo dirigido por el investigador principal y un grupo de estudiantes de arquitectura de la Universidad de La Salle, en una prueba piloto que correspondió a 10 unidades habitacionales y cuyos resultados permitieron conformar la versión final del instrumento a aplicar en el trabajo de campo.

El diseño de la colección de fichas para la recogida de información directa fue asesorado por un equipo multidisciplinario de arquitectos, metodólogos, trabajadores sociales, economistas y un especialista en estadística. Así, las fichas se estructuraron en 6 acápites, donde se mezcla la información obtenida de la observación directa por parte del profesional que las llena y de las apreciaciones que este recoge a partir de la información brindada por los usuarios: 
- Información general del proyecto

- Caracterización de la vivienda

- Descripción de los espacios en la vivienda

- Relación con el contexto en el que se desarrolla la vivienda

- Caracterización del usuario y su hogar

- Deseos y satisfacción de los ocupantes

\section{DESARROLLO DEL TRABAJO DE CAMPO}

El coordinador de cada equipo, responsable de la selección final de las soluciones habitacionales a muestrear, debía a su vez recopilar determinada información general sobre los proyectos y las zonas urbanas: normativa, manzanas catastrales, planos a diferentes escalas del barrio y sus alrededores, material fotográfico aéreo y secuencial. Cada profesional que participaba directamente en la recopilación de información también debía completar datos necesarios en cada ficha antes de comenzar el trabajo de campo.

La recogida de información en cada vivienda visitada incluía los datos obtenidos de las preguntas a los usuarios, la observación y medición directa por parte del profesional, así como sus propias valoraciones. Esta acción tuvo una duración aproximada de 40 minutos en cada visita y requería de la aprobación previa del jefe de hogar y/o su cónyugue.

\section{FOTO 1. TRABAJO DE CAMPO}

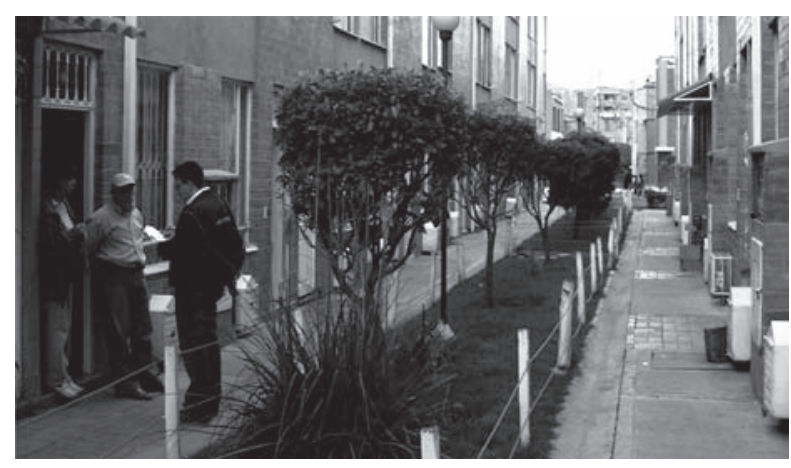

FUENTE: Archivo del autor.

Tanto los profesionales que elaboraron las fichas como los coordinadores de cada equipo recibieron una guía metodológica y conceptual, y fueron capacitados mediante el desarrollo de talleres para la realización del trabajo de campo, que fue además controlado y supervisado por cada coordinador.

\section{CONSULTA A EXPERTOS.}

Los resultados del procesamiento de la información obtenida permitieron identificar los parámetros de las variables estudiadas con respecto a la caracterización de las soluciones habitacionales que mayor impacto tienen en su calidad, expresada a través de la satisfacción de los usuarios. Estos parámetros fueron sometidos a consulta de expertos mediante 
el método Regnier ${ }^{15}$, para obtener indicadores que permitan verificar la importancia relativa de cada uno de ellos.

El procedimiento de consulta es individual, para evitar protagonismos propios de la confrontación intelectual, y requiere de poco tiempo de dedicación por parte del experto consultado. Las opiniones consignadas, de valor significativo para los objetivos del instrumento y su procesamiento, son citadas de forma textual, evitando el predominio de intereses personales en las interpretaciones o juicios de valor.

A partir de una revisión bibliográfica y en bases de datos, así como consultas a personalidades del diseño y la construcción en la ciudad y a otras personas vinculadas a la problemática habitacional de Bogotá, se identificaron 36 individuos con una experiencia o práctica profesional en el campo de la vivienda social de más de 20 años, y/o docentes e investigadores con categoría científica vinculados a la temática en institutos y mesas de trabajo de reconocidas universidades. De ellos, 10 actuaron como expertos, ya que 5 superaron el porcentaje de respuestas donde el experto tenía información pero no deseaba participar, 6 expresaron que por sus responsabilidades

15 Este método proporciona de forma sencilla y ágil la opinión de los participantes en una escala de valores identificada por los colores del semáforo.

108 revista invi № 72 / Agosto 2011 / Volumen № 26: 95-126 actuales en cargos gubernamentales pudieran generarse conflictos de interés, y el resto no respondió.

\section{Resultados}

\section{CARACTERIZACIÓN DE LA MUESTRA}

Las diferentes modalidades VIS encontradas en la muestra seleccionada fueron promovidas entre el 2000 y el 2007 en Bogotá por treinta constructoras diferentes. Se destacan la constructora Bolivar, con un 43,3\% de viviendas construidas; Las Galias, con el 26,7\%; y Amarilo, con el 24,3\%. Las demás constructoras tienen menos del $17 \%$ de Viviendas de Interés Social construidas en el período estudiado.

Las soluciones que conforman la muestra corresponden a los estratos socioeconómicos ${ }^{16} 2$ (52\%) y 3 (46\%). No se encontraron soluciones de estrato 1. El tipo apartamentos se encuentran en su mayoría en el estrato 3, mientras que el mayor porcentaje del tipo casa está en el estrato 2. En las áreas urbanas al norte y occidente de la ciudad predominan las viviendas de estrato socioeconómico 3, mientras en el sur sobresalen las de estrato 2 y en las áreas urbanas centrales existen ambas.

16 En Colombia son una herramienta que utiliza el Estado (Ley 142 de 1994, artículo 102) para clasificar los inmuebles residenciales. La clasificación por estratos que obtenga una persona determina los impuestos que debe pagar y las tarifas de los servicios públicos domiciliarios, entre otros. Los estratos 1 y 2 , y algunas veces el 3, son subsidiados por los estratos 4,5 y 6 , y obtienen varios beneficios del Estado.

ARTÍCULO: La calidad del hábitat para la vivienda de interés social. Soluciones desarrolladas entre el 2000 y el 2007 en Bogotá / Alex Leandro Pérez Pérez 
FOTO 2. TIPO CASA

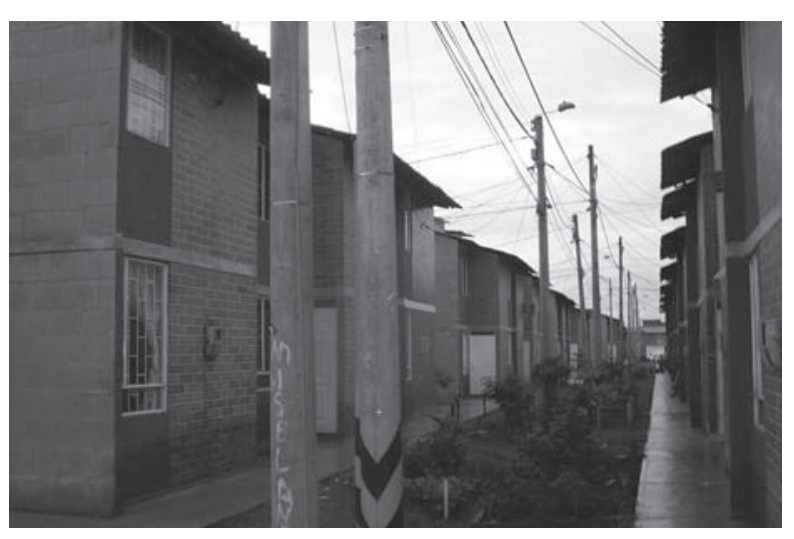

FUENTE: Archivo del autor.

\section{FOTO 3. TIPO APARTAMENTOS}

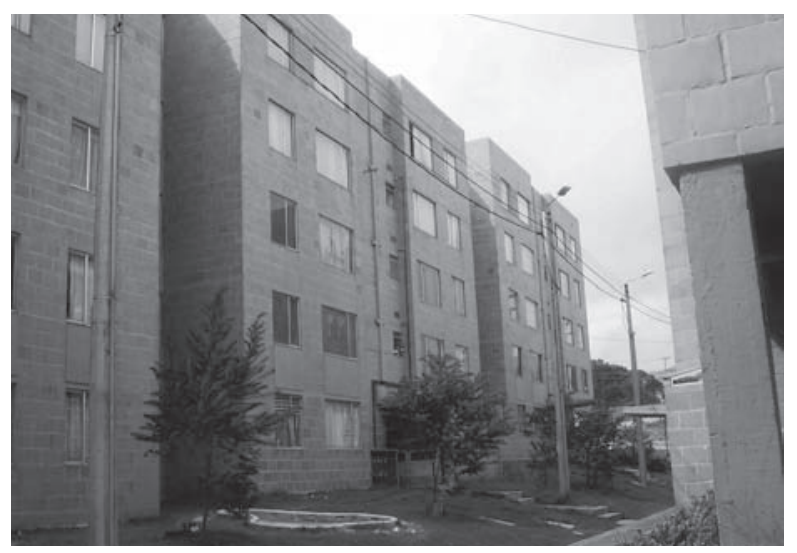

FUENTE: Archivo del autor.
La Ley 3 de 1992 y el Decreto 975 de 2004 establecen tipos de vivienda de acuerdo con su costo, donde el Tipo I se encuentra entre 0 y 50 Salarios Mínimos Legales Vigentes (SMLV) y el Tipo IV entre 121 y $135 \mathrm{SMLV}^{17}$. El 40\% de las viviendas que conforman la muestra son de Tipo I, aproximadamente el 35\% de tipo II o III y menos del 5\% de Tipo IV.

\section{CARACTERIZACIÓN DEL USUARIO}

De manera general, las viviendas están habitadas por un grupo familiar conformado por 4 ó 5 personas, en su mayoría menores de 55 años. Las pocas viviendas donde habitan dos núcleos familiares son casas en las cuales viven entre 4 y 7 personas.

Las Viviendas de Interés Social en general son habitadas por personas que trabajan como empleados, aunque también existen familias que tienen, además, actividades económicas independientes. En las viviendas donde la mayoría o todas las personas productivamente activas son empleadas, los gastos oscilan entre $\$ 850.000$ (425 USD) y $\$ 1.040 .000$ (520 USD), con un promedio de $\$ 920.000$ (460 USD), mientras que en las viviendas en donde hay usuarios con actividades

17 Los tipos I, II, III y IV corresponden al valor de la vivienda (los cuales se indicaran aquí en dólares con un valor promedio en el período de estudio), y se constituyen en un indicador indirecto para la calidad, los cuales corresponden a: Tipo I entre 0 y 50 Salarios Mínimos Legales Vigentes SMLV, 9 mil USD; Tipo II entre 51 y 70 SMLV, 12500 USD; Tipo III entre 71 y 100 SMLV, 18 mil USD; y Tipo IV entre 101 y 135 SMLV, 24 mil USD. 
económicas independientes, los gastos mensuales son muy variables, oscilando entre \$650.000 (325 USD) y $\$ 1.050 .000$ (525 USD), con un promedio de $\$ 830.000$ (415 USD).

En el $45 \%$ de las viviendas que conforman la muestra habitan usuarios con nivel académico universitario y en el 4\% personas con estudios de postgrado. Los que habitan las Viviendas de Interés Social que conforman la muestra en Bogotá no son víctimas del desplazamiento forzado ${ }^{18}$.

\section{CARACTERIZACIÓN DE LA VIVIENDA}

El numero de espacios funcionales (habitaciones, baños, sala, comedor, estudio, entre otros) con los que contaba la vivienda en el momento de su adquisición era más variable en las tipo I y II (entre 6 y 8); las viviendas tipo III tenían 7 u 8 espacios y todas las viviendas tipo IV estaban conformadas por 8 espacios. Por otro lado, existe una relación directa entre la solución habitacional y el número de espacios, de manera que las casas poseen más espacios que los apartamentos.

Tanto en casas como en apartamentos es frecuente encontrar la combinación espacial de sala-comedor. Los espacios como cocina-comedor o sala-

18 Los ciudadanos colombianos, y en especial los que habitan áreas rurales, sufren desde hace más de 50 años una guerra entre grupos armados al margen de la ley y el Estado, que ha provocado por generaciones una migración sistemática del campo a la ciudad, convirtiendo a esta población en la más vulnerable económicamente.

110 revista invi № 72 / Agosto 2011 / Volumen № 26: 95-126 cocina-comedor no son muy frecuentes, y cuando existen están en apartamentos.

Para los efectos de esta investigación las posibles soluciones constructivas se clasificaron en:

- Laminar: todos los considerados dentro del sistema constructivo de moldeos continuos, paneles prefabricados y paneles izados in situ

- Macizos:ubicadosdentrodelossistemasdemampostería reforzada, confinado, de diafragma, parcialmente reforzados y totalmente reforzados.

- Entramados: sistemas a base de pórticos.

Los sistemas laminares y de entramado son más frecuentes empleados en los apartamentos, mientras que los macizos son usados tanto en casas como en apartamentos casi en igual porcentaje.

Aproximadamente el 70\% de las soluciones habitacionales tienen servicios complementarios, como televisión por cable, parabólica o satelital y el 35\% adquirieron el acceso a internet.

\section{CARACTERIZACIÓN DEL ENTORNO}

Con independencia del área urbana donde habiten, el medio más utilizado por los usuarios para trasladarse a las áreas urbanas centrales de Bogotá 
es el transporte público. Los que viven al norte de la ciudad son quienes gastan más tiempo en transportarse al centro (más de 41 minutos), seguidos de quienes se ubican al occidente. Lo mismo sucede con el transporte a los centros de trabajo o estudio, aunque los que viven en zonas centrales lo pueden hacer caminando.

\section{GRÁFICO 1. UBICACIÓN EN LA CIUDAD Y MEDIO DE TRANSPORTE UTILIZADO PARA LA MOVILIDAD AL TRABAJO $O$ ESTUDIO. COMPORTAMIENTO DEL 100\% DE LA MUESTRA EN LOS ÍTEMS.}

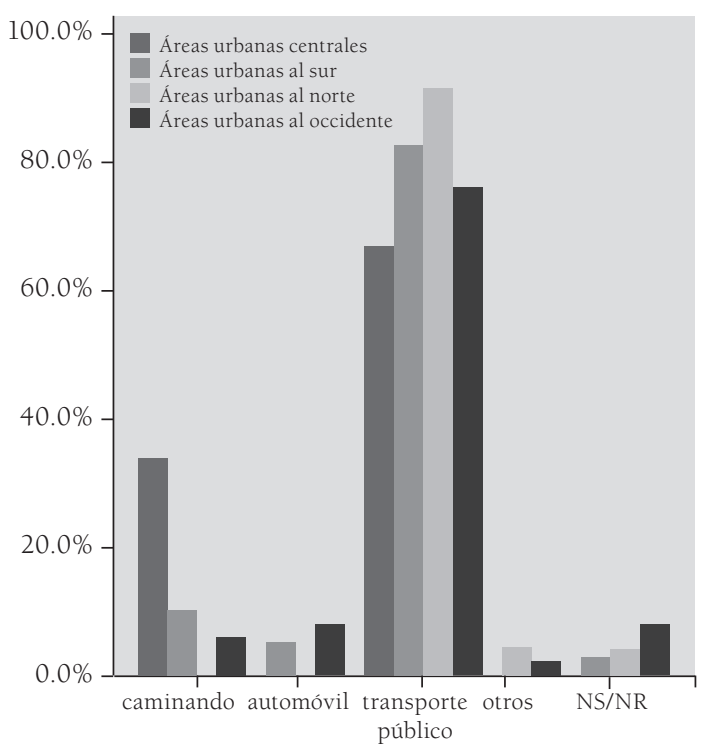

FUENTE: Procesamiento de los resultados de la investigación.
La mayoría de los usuarios, independientemente de su ubicación en la ciudad, tienen cerca de sus viviendas servicios financieros a los cuales pueden acceder caminando, excepto quienes viven en las áreas urbanas centrales de la ciudad, donde, contradictoriamente, el 50\% toma transporte público para acceder a estos servicios.

Se observó que no existe una relación directa entre el sector donde se ubica la vivienda y el acceso a los servicios de salud. No obstante, quienes viven en áreas urbanas al centro o al norte de la ciudad tienen más fácil acceso a servicios de salud que los que se localizan en otros puntos, como el sur o el occidente.

El transporte público es utilizado con más frecuencia para acceder a servicios de recreación pasiva al sur de la ciudad, mientras que al norte y al occidente es más usual ir caminando, y en el centro ambos. Teniendo en cuenta los resultados del análisis de correspondencia y el tiempo que utilizan para transportarse a estos servicios, se puede concluir que el sur de la ciudad tiene carencias en servicios de recreación pasiva, entendida esta como cines, teatros, anfiteatros y zonas verdes para el descanso, entre otros.

El sector de la ciudad en el que hay menos dificultad para acceder a servicios de recreación activa (canchas deportivas al aire libre, polideportivos, parques de diversiones y otros) es el centro, pero 
en general existe insuficiencia de estos servicios cerca de las viviendas de interés social en Bogotá.

En resumen, la mayoría de las urbanizaciones de interés social en Bogotá cuentan con más de 6 rutas de transporte público, pero son los habitantes de las áreas urbanas centrales quienes mejor accesibilidad tienen con respecto al resto de la ciudad.

\section{Discusión}

\section{SATISFACCIÓN DE LAS EXPECTATIVAS DEL USUARIO}

El porcentaje de personas que adquirió vivienda en cada año durante el período de estudio es uniforme. Con respecto a las modificaciones que los usuarios realizan en las viviendas, se aprecia que las familias demoran aproximadamente cuatro años en realizar grandes inversiones económicas en el acondicionamiento de su vivienda.

Las familias que adquirieron una vivienda con posibilidad de modificación o ampliación, en general, le han añadido 3 ó 4 espacios, mientras que quienes no recibieron soluciones habitacionales con esa opción, de igual modo han adicionado entre 1 y 2 locales.

112 revista invi № 72 / Agosto 2011 / Volumen № 26: 95-126

\section{GRÁFICO 2. POSIBILIDAD DE CRECIMIENTO VS. CANTIDAD DE ESPACIOS MODIFICADOS. COMPORTAMIENTO DEL 100\% DE LA MUESTRA EN LOS ÍTEMS.}

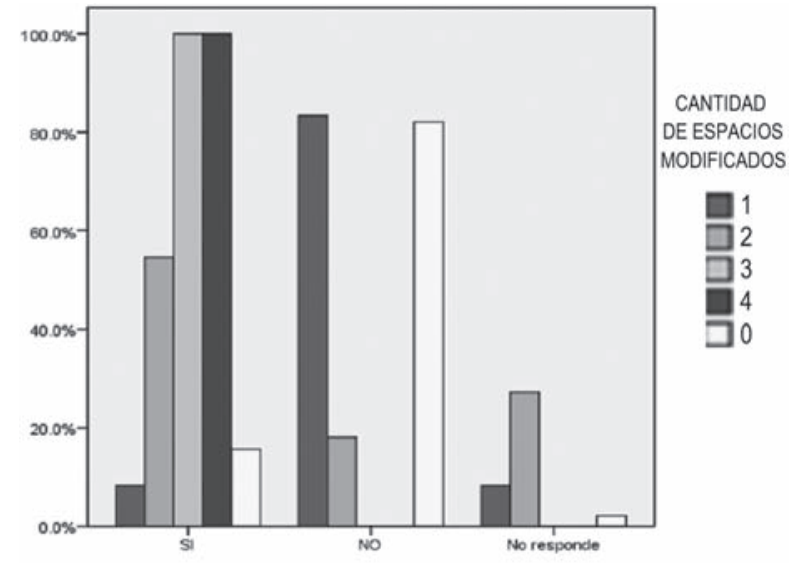

¿EL PROMOTOR O LA CONSTRUCTORA AL VENDER LA VIVIENDA OFRECIÓ ALGUNA POSIBILIDAD PARA SU CRECIMIENTO?

FUENTE: Procesamiento de los resultados de la investigación.

En términos generales, muy pocas son las ofertas de vivienda de interés social que favorecen la trasformación para adecuarse a los requerimientos cambiantes de las familias, lo cual demuestra la poca atención que se brinda a las particularidades de los sectores de bajos ingresos económicos en cuanto a su diversidad poblacional y familiar. 
Entre los diferentes aspectos que los usuarios consideran que necesitan sus viviendas se destacan tres: espacios más amplios, necesidad de otro(s) espacio(s) y mejores acabados. Quienes pueden ampliar sus viviendas son los que viven en casas, mientras que solo un bajo porcentaje de los que habitan en apartamentos puede realizar ampliaciones espaciales, lo que ejecutan con mayor frecuencia siendo mejoras en los acabados.

En general, quienes están más conformes con la vivienda viven en apartamentos más del 40\% considera que no les hace falta nada, y quienes piensan que les hace falta algo en general quisieran más espacios o ampliación de los ya existentes. Los que viven en casas, además de desear más espacios y ampliación, opinan que sus viviendas carecen de acabados adecuados.

Se observa en las soluciones habitacionales analizadas una reducción espacial para la vivienda de interés social que provoca en los beneficiarios rechazo o resignación.

El mercado inmobiliario especulativo contribuye al incremento de la demanda de VIS, al facilitarles a los compradores un menor precio a pagar por la vivienda adquirida, pero esto va aparejado de una reducción de la calidad, al disminuir aún más las áreas de los espacios así como la subdivisión de los lotes para lograr usufructuar mayores ganancias. Es decir, a mayor densidad, mayor oferta constructiva, mayor demanda y menores precios.

\section{CONFORT}

Más del 70\% de los usuarios de las viviendas de interés social escuchan los ruidos de sus vecinos, y quienes más sufren de este tipo de problemas de privacidad viven en apartamentos, aunque no existe una diferencia considerable en este sentido entre ambos tipos de soluciones habitacionales.

Esta condición pudiera estar ligada al sistema constructivo y la distribución espacial en las viviendas, que afectan las condiciones de privacidad necesarias para su debido funcionamiento. El aislamiento acústico y una disposición espacial que favorezca la intimidad y dignidad tanto individual como de la familia dentro de la vivienda, no son opciones planificadas por el ejercicio profesional de diseño y construcción en la muestra estudiada.

Ante la pregunta "¿en qué lugar del barrio se siente mejor?" los usuarios coinciden que el mejor lugar son sus propias viviendas, aunque también muestran satisfacción por las urbanizaciones donde conviven. En las áreas urbanas centrales de la ciudad los espacios verdes no son una opción de bienestar dentro del barrio.

De manera general, los usuarios están conformes con la ubicación de su vivienda, particularmente los que viven en el centro. No obstante, casi la mitad preferirían vivir fuera de la ciudad.

La mayoría de las personas consideran que sus viviendas gozan de buena iluminación en sus dife- 
rentes espacios, excepto algunos (cerca de 37\%) que plantean que les hace falta iluminación en los baños.

\section{FUNCIONALIDAD ESPACIAL (DIMENSIONES Y RELACIONES)}

Aproximadamente la tercera parte de los usuarios consideran que sus dormitorios no tienen capacidad para dos camas, sino para una cama semidoble que permita una buena circulación alrededor de ella, y el 50\% manifiesta que no tienen espacio para el almacenamiento (closet) o que el existente es insuficiente. Por otra parte consideran que la cocina, al contrario de la sala y el comedor, cumple mejor las necesidades de espacio para acomodar enseres y equipamiento sin interrumpir la circulación.

El 45\% de las viviendas estudiadas no tienen en la actualidad un espacio especializado para lavar y secar la ropa, porque han transformado la función original del área de lavadero que inicialmente existía de acuerdo con el programa arquitectónico.

Al desaparecer la zona destinada para las actividades especificas del lavado y secado de ropa, que también incluye otras actividades como el almacenamiento de enseres y elementos para el aseo, no solo se afecta el uso-función propio de este espacio, sino también la relación interior-exterior (iluminación y ventilación), que reduce las condiciones de habitabilidad y confort en la vivienda.

Otro aspecto en el desarrollo funcional de la vivienda y que no se considera en las soluciones ha- bitacionales es el de las barreras arquitectónicas que excluyen a los discapacitados y otros sectores de la población (niños y adultos mayores).

Solo al 20\% de los usuarios se les ofreció alguna posibilidad para el crecimiento de su vivienda al adquirirla, de los cuales el 30\% tienen una actividad económica y productiva en el hogar, lo cual se presenta también en un 5\% de quienes no recibieron este tipo de oferta. El total de las personas que realizan actividades productivas habitan en casas.

No se observa en la muestra estudiada que las familias puedan acondicionar sus viviendas para el sustento económico, y cuando lo realizan, deben prescindir de áreas de uso colectivo dentro del programa espacial.

\section{FOTO 4. EVOLUCIÓN DEL HÁBITAT RESIDENCIAL. VIVIENDAS CON ACTIVIDAD PRODUCTIVA Y EN PROCESO DE CONSOLIDACIÓN}

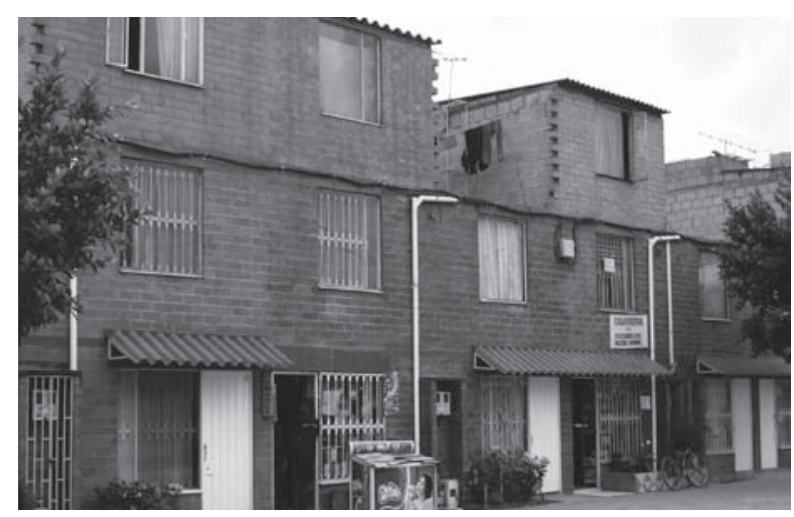

FUENTE: Archivo del autor. 


\section{HIGIENE Y LIMPIEZA}

Los usuarios consideran que al recibir sus viviendas los pisos y paredes no eran de fácil limpieza para mantener la higiene, siendo la cocina y los baños los espacios funcionales que en algunas ocasiones mejoran esta apreciación. En general, la oferta actual de viviendas es entregada con terminaciones que no satisfacen en su totalidad las condiciones para el mantenimiento adecuado de las superficies en la vivienda, provocando la inmediata necesidad de invertir en acabados que mejoren esta condición.

\section{DIFERENCIA COSTO COMPRA-VALORACIÓN ACTUAL Y CONSIDERACIONES ECONÓMICAS.}

El 80\% de las personas opinan que fue sencillo el procedimiento de adquisición de la vivienda, considerando que el grado de dificultad no dependió del hecho de solicitar y utilizar el subsidio familiar. En este sentido, es necesario tener en cuenta que los usuarios de las soluciones habitacionales estudiadas no son los más vulnerables de la sociedad, por lo cual este resultado no refleja la efectividad de los medios y mecanismos para la financiación de una vivienda digna para los sectores de más bajos ingresos económicos (estrato 1).

En general, las personas consideran que sus viviendas se han valorizado en promedio un 37\% por encima de su precio original, en dependencia de su tipo. Los usuarios que tienen casas consideran que se valorizaron entre el 35\% y el $45 \%$, mientras quienes tienen apartamentos piensan que esta valorización está entre el 30 y el 35\%.

La valorización también varía según el costo. Para quienes adquirieron una vivienda tipo I o II, esta es de aproximadamente el $40 \%$, para quienes tienen una tipo III es del $20 \%$, pero no hay consenso con respecto a las tipo IV: para algunos se han devaluado hasta el $4 \%$ y para otros han incrementado su valor hasta en un 55\%. Para las viviendas tipo I, II y III la valorización está relacionada con el mejoramiento y modificaciones que los usuarios le han realizado, mientras que las viviendas tipo IV dependen sobre todo de aspectos como la ubicación y el contexto urbano y social donde se encuentran.

Los costos derivados de la movilidad y acceso de los usuarios a los servicios (productivos, económicos, financieros, de salud, entre otros) debido a su ubicación en la periferia y las distancias a recorrer para suplir sus necesidades en la ciudad, afectan la economía básica de las familias.

\section{GUSTOS Y PREFERENCIAS}

Entre las opciones registradas ante la pregunta "¿qué cambiaría del entorno de su vivienda?", se resaltan cinco aspectos; más zonas verdes, algunos servicios de escala barrial, espacios públicos, el 
ruido y la inseguridad. La mayoría de los usuarios consideran muy importante en el entorno el hecho de estar rodeados de zonas verdes.

Un alto porcentaje de casas tienen la posibilidad de observar espacios verdes desde sus viviendas, lo que no ocurre con los apartamentos. Es por ello que aunque en general se observa un alto grado de conformidad con el contexto, quienes viven en apartamentos desearían más zonas verdes y quienes tienen la posibilidad de observar áreas verdes desde su vivienda están más conformes.

Entre las opciones registradas ante la pregunta "iqué espacios le hacen falta o desearía en su vivienda?", resaltan seis opciones: más área para los espacios actuales, baño(s), alcoba(s), espacio de uso múltiple interior, espacio de uso múltiple exterior y garaje. Los que viven en apartamentos consideran que una de sus mayores carencias son los espacios de uso múltiple exterior en la vivienda (balcones o terrazas), mientras que los que viven en casas piensan que les hacen falta más habitaciones. Otros aspectos como más área en espacios o garaje son más importantes para quienes tienen casa que para quienes tienen apartamento.

\section{GRÁFICO 3. QUÉ ESPACIOS LE HACEN FALTA 0 DESEARÍA EN SU VIVIENDA. COMPORTAMIENTO DEL 100\% DE LA MUESTRA SEGÚN ÍTEMS}

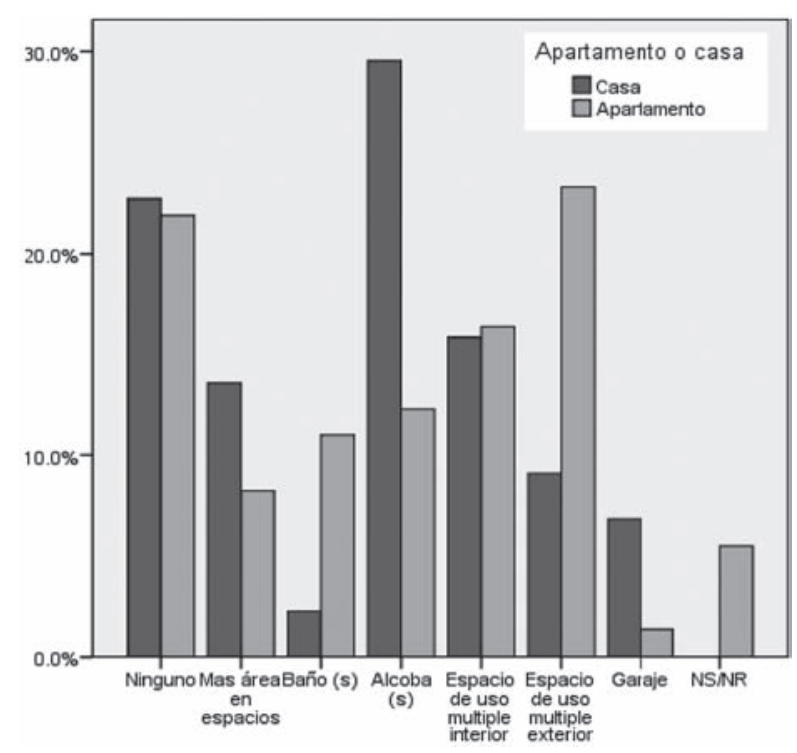

FUENTE: Procesamiento de los resultados de la investigación.

Portanto, seobservanen losesquemasactualesdeorganización espacial propuestas rígidas que no permiten funciones múltiples o la libre modificación por el usuario para satisfacer las necesidades actuales o futuras. 
Para la mayoría de las personas consultadas el lugar más confortable de la vivienda son las habitaciones, y disfrutan estar en estas o en la sala comedor. Respecto a la preferencia por sala-comedor, cocina-comedor sala-cocina-comedor, no se evidencia favoritismo por algún tipo particular de estos.

Un 70\% de los usuarios escuchan las actividades de los vecinos, pero están divididas las opiniones respecto a si les molesta o no.

\section{COSTUMBRES Y TRADICIONES}

Más del $80 \%$ de las personas han podido mantener sus hábitos y costumbres, y el 70\% no ha tenido que modificar la vivienda para conservar su estilo de vida. Cerca del 70\% de los usuarios no han cambiado su ocupación laboral después de la llegada a la nueva vivienda, es decir que la nueva vivienda en general no ha influido en la ocupación laboral.

El $70 \%$ de los usuarios consideran que su estilo de vida ha cambiado para bien con la llegada a su nueva vivienda. Aunque las opiniones con respecto a si las relaciones entre los miembros de la familia han cambiado, están divididas, existe cierta tendencia a considerar que han cambiado favorablemente.

La mayor parte de las personas antes de adquirir la nueva casa vivían en arriendo (72\%) o en la casa de la familia $(20,5 \%)$ y solo un bajo porcentaje tenía vivienda propia (6\%).

\section{RELACIÓN PRESENTE, PASADO Y FUTURO}

La mayoría de las viviendas de interés social se ubican en el sur y en el occidente de la ciudad. Se observa que las personas adquirieron las soluciones habitacionales en la misma zona urbana donde habitaban. Los usuarios de este tipo de viviendas en el occidente de la ciudad provienen de esta zona o de municipios cercanos a Bogotá

La mayoría de los consultados considera que nada de su vivienda anterior es fundamental para mantener en la actual, pero opinan que hacen falta espacios y/o mayor área en las actuales. Solo un bajo porcentaje (15\%) considera que su vivienda actual es menos cómoda que la anterior, para los demás es igual o, en general, es más cómoda.

A la pregunta de si han cambiado las rutinas del grupo familiar en las horas de comida, en las celebraciones especiales, en las conversaciones familiares o en los momentos de intimidad, la mayoría de los usuarios consideran que las rutinas familiares no han cambiado, lo cual aprecian como un hecho positivo.

Aunque las relaciones con los vecinos han sido en general buenas en la vivienda anterior, se nota que han sido mejores en la nueva. 


\section{GRÁFICO 4. RELACIÓN ENTRE LA VIVIENDA PASADA Y LA VIVIENDA DE SUS SUEÑOS. COMPORTAMIENTO DEL 100\% DE LA MUESTRA SEGÚN ÍTEMS}

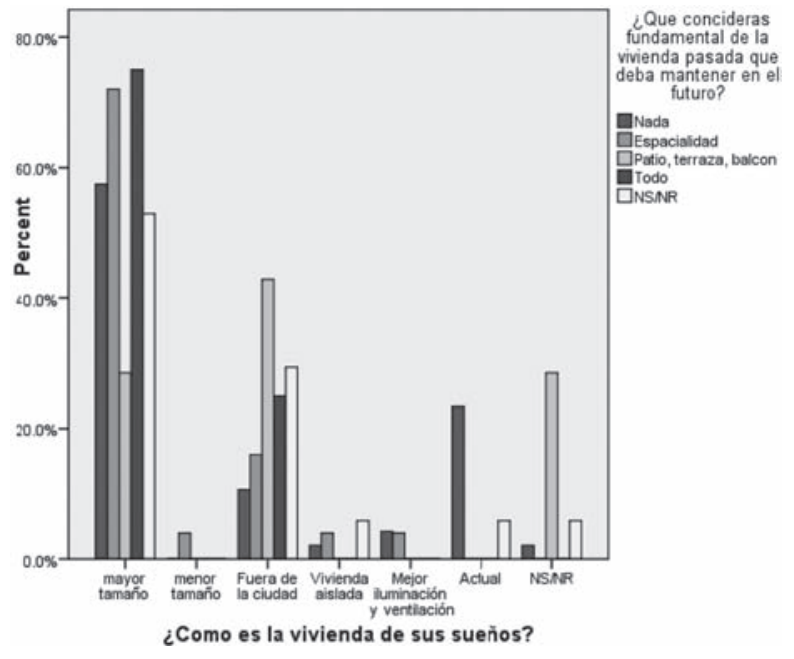

FUENTE: Procesamiento de los resultados de la investigación.

\section{MORFOLOGÍA Y TIPOLOGÍA URBANA Y AROUITECTÓNICA}

Los desarrollos habitacionales insertos en espacios disponibles de las zonas consolidadas o en consolidación de la ciudad, no logran la integración tipológica volumétrica o de relaciones con el contexto arquitectónico y urbano existente. No se observa, por tanto, una preocupación de diseño para im-
GRÁFICO 5. RELACIÓN ENTRE LAS NECESIDADES DE LA VIVIENDA ACTUAL Y LAS CONDICIONES DE LA VIVIENDA PASADA OUE DEBIERA MANTENER EN EL FUTURO. COMPORTAMIENTO DEL 100\% DE LA MUESTRA SEGÚN ÍTEMS

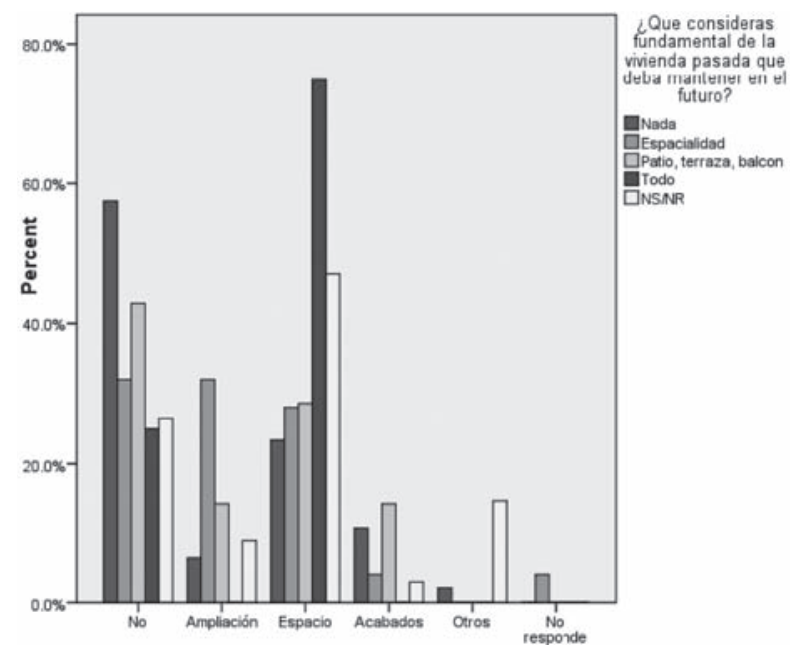

FUENTE: Procesamiento de los resultados de la investigación.

pactar favorablemente el hábitat donde las soluciones VIS deben insertarse.

En la ciudad se manifiesta una negativa diferenciación con respecto a otro tipo de soluciones habitacionales (no VIS), evidenciándose una pobre arquitectura para los sectores de bajos ingresos, lo cual afecta posteriormente los futuros procesos de valorización económica. Sin embargo, está demos- 
trado que es posible ofrecer una buena arquitectura también para estos estratos sociales (Aravena, 2005; Equipo arquitectura, 2005).

En propuestas urbanas como las desarrolladas por Metrovivienda, la organización y el diseño de las zonas públicas y recreativas mejoran considerablemente la percepción de la calidad, pero en los espacios públicos o comunales de las urbanizaciones o conjuntos residenciales aislados dentro de la trama urbana mejorar esta condición no es una preocupación. Se cuestiona la importancia que otorgan los profesionales al diseño de las áreas comunes y si las consideran como determinantes para la calidad del entorno y la asociación de los habitantes.

Las soluciones de vivienda de interés social que componen la muestra se ubican en su gran mayoría en áreas periféricas, por su directa relación con el valor del suelo. Cuando se recopiló información sobre la actividad constructiva en la ciudad resultó difícil encontrar ejemplos de VIS en áreas urbanas centrales. Sin embargo, continuar extendiendo la ciudad mediante nuevos desarrollos de vivienda de interés social en la periferia conspira contra la necesaria protección del suelo agrícola.

\section{APORTES ESTÉTICOS Y TÉCNICO- CONSTRUCTIVOS}

En términos generales se observa poca preocupación por proponer alternativas volumétricas y funcionales con mejor calidad de diseño para este tipo de viviendas, a excepción de algunas soluciones multifamiliares. Los servicios comunes, como jardines infantiles, salones comunales y otros, adquieren poca importancia en el planeamiento de la urbanización, ubicándolos por lo general en zonas residuales, en esquemas habitacionales repetitivos o con propuestas sin ninguna preocupación formal.

No se observan iniciativas de diseño paisajístico que promuevan el bienestar y favorezcan la delimitación y buen uso de las áreas públicas o comunales.

La positiva evolución de la vivienda está directamente ligada a su planeamiento estructural y técnico-constructivo, el cual contiene en sus principios las posibilidades y limitaciones para la transformación de las viviendas. Sin embargo, los aportes en las alternativas actuales son insuficientes para responder a las necesidades que demanda la producción de una vivienda de alta calidad, lo cual requiere esfuerzos en el proceso de investigación científica y tecnológica.

\section{RESPUESTA A LAS NECESIDADES Y ASPIRACIONES DEL USUARIO}

El promotor o la constructora ofrecieron posibilidades para el crecimiento de la vivienda que son viables, pero no satisfacen las necesidades de la 
FIGURA 5. FICHA RESUMEN URBANIZACIÓN

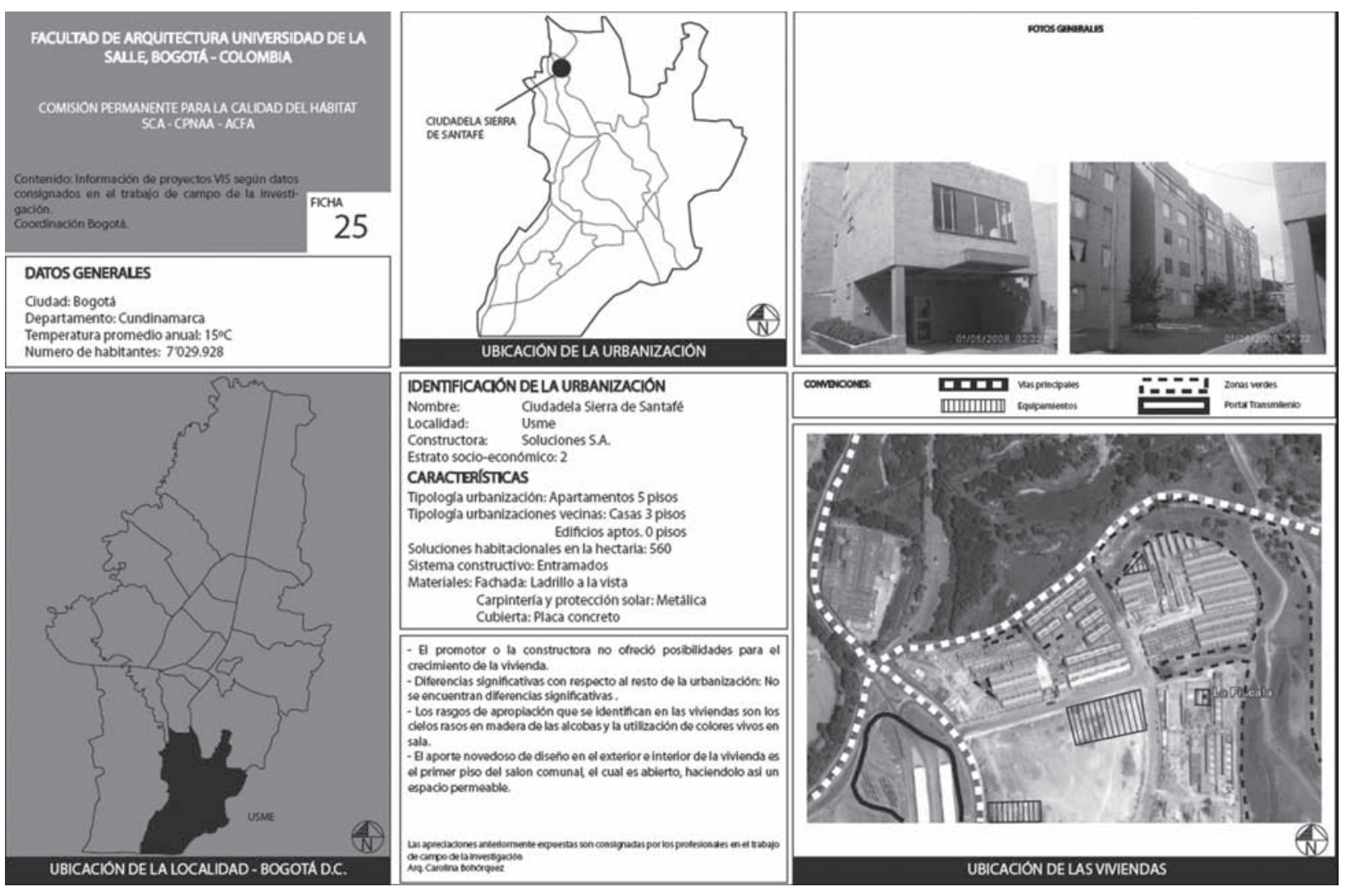

FUENTE: Procesamiento de la información en la investigación. 
familia o esta no cuenta con los recursos para realizarlas. Quienes optaron por aumentar el área de su casa y cuentan con los recursos, han utilizado también la cubierta, generando nuevas habitaciones o terrazas no previstas en el proyecto y expansión original.

La homogenización de la vivienda de interés social desconoce las particularidades socioculturales de los beneficiarios, que se expresan en la práctica cotidiana de los usuarios que transforman las edificaciones, atentando contra la estabilidad estructural a riesgo de su propia vida.

La cantidad de alternativas habitacionales diferentes en la urbanización al momento de la compra, en general tanto en casas como en apartamentos, oscila entre 1 y 2 opciones, los pocos casos en que hay 3 es más frecuentemente en apartamentos. En ningún caso se encontraron más de tres alternativas. Esto demuestra una concepción rígida de tipificación para la VIS que no ofrece alternativas para las familias y promueve un entorno urbano monótono.

Existen rasgos de apropiación de las viviendas que se manifiestan mediante una gama de elementos de la cultura popular, como balaustradas, arcos, falso techos, ornamentaciones y colores diferentes en cada uno de los espacios, que manifiestan, además, las inclinaciones estéticas individuales. Sin embargo, esto difícilmente se encuentra al exterior de las viviendas, ya que la comunidad ha exigido conservarlas en su estado original.

Se observa una tendencia por encerrar las áreas públicas para convertirlas en comunales y contratar servicios de vigilancia privada. Esto puede evidenciar que las soluciones urbano-arquitectónicas no han delimitado con claridad el área comunal de las públicas, generándole a los usuarios percepciones de inseguridad que exigen la transformación de su entorno, obviando las regulaciones y aumentando los costos de mantenimiento y administración.

\section{IMPORTANCIA RELATIVA DE LOS PARÁMETROS DE LA CARACTERIZACIÓN DE LAS SOLUCIONES HABITACIONALES EN LA CALIDAD, EXPRESADA A TRAVÉS DE LA SATISFACCIÓN DE LOS USUARIOS SEGÚN CRITERIO DE EXPERTOS}

Con independencia de la discusión de los resultados particulares que arrojó el trabajo de campo, la información recopilada y procesada permitió establecer relaciones de dependencia entre los parámetros que caracterizan las soluciones habitacionales y la calidad expresada a través de la satisfacción de las personas. El resumen de los principales indicadores encontrados fue sometido a consulta de expertos, con vistas a establecer los parámetros según su importancia para Bogotá, que luego serían discutidos en el resto de las regiones del país. 


\section{Parámetros de las soluciones habitacionales con MAYOR INFLUENCIA EN LA CALIDAD}

El 90\% de los expertos consideran que hay tres parámetros con una gran influencia en la calidad del hábitat de la vivienda de interés social: tipología de la vivienda (apartamento, casa), privacidad y vivienda evolutiva (progresión espacial)

Los cinco parámetros clasificados en un segundo nivel de influencia según el 80\% de los expertos son: acceso a servicios públicos básicos, espacialidad en la vivienda (número de espacios y/o ambientes), diseño constructivo (tipología constructiva y materiales), accesibilidad para discapacitados y, finalmente, la movilidad (vías de acceso y/o urbanización, transporte público).

Otros siete parámetros que el $70 \%$ de los expertos consideraron en un tercer nivel de relevancia son: la flexibilidad espacial, área del lote, morfología de la vivienda (forma), relación vivienda/servicios, adaptabilidad a las necesidades demográficas de la familia, productividad económica en la vivienda, relación vivienda/trabajo y estudio.

\section{Parámetros de las soluciones habitacionales con MENOR INFLUENCIA EN LA CALIDAD}

Los otros parámetros, que no inciden en forma determinante en la calidad de la vivienda de interés social según los expertos, son: variedad de ofertas en la urbanización, distribución espacial, variedad de ofertas en la ciudad y adaptabilidad cultural en la vivienda.

Finalmente, el parámetro que menos incide según los expertos para la evaluación de la calidad del hábitat de la vivienda es la adaptabilidad estética de la vivienda.

\section{Conclusiones finales}

Resulta imprescindible para la evaluación de la calidad en la vivienda de interés social incorporar la satisfacción de las necesidades y expectativas del usuario mediante una línea de tiempo que considere las necesidades actuales y las expectativas futuras de este. Se identifica además la relación de la satisfacción de las necesidades con las de la vida en comunidad y su necesaria integración con el medio, lo que demanda de la vivienda como solución de diseño un enfoque amplio que involucre la escala urbana y arquitectónica.

Luego de la evaluación general de la calidad de la Vivienda de Interés Social en Bogotá en el período considerado, en función de la percepción de los usuarios pudieran sintetizarse tres aspectos fundamentales: la responsabilidad de los profesionales con los beneficiarios; la participación de los usuarios en la producción y trasformación de su hábitat; y la calidad integral del hábitat. 
Ante la responsabilidad de los profesionales con los usuarios se observa cómo se condiciona la calidad de la vivienda y el hábitat debido a las dinámicas del mercado inmobiliario, permitiendo que los profesionales se constituyan en una fuerza de trabajo independiente, opuesta a la de los usuarios, ya que los proyectos de vivienda de interés social no responden adecuadamente a sus necesidades básicas.

Entre los aspectos más relevantes se identifica la falta de exploración tanto desde el punto de vista del diseño como de las soluciones técnico-constructivas, ya que las alternativas propuestas no incorporan soluciones flexibles, como la opción para el crecimiento y la adaptabilidad de los espacios, iniciativas reconocidas en la producción del hábitat para los sectores de bajos ingresos que se adaptan a las características cambiantes de la familia en el tiempo.

La muestra también se caracteriza por una pobre imagen estética, acabados que no facilitan su mantenimiento, limpieza e higiene, y espacios reducidos insuficientes para satisfacer las necesidades de los usuarios, prevaleciendo así la postura de condiciones mínimas en una unidad mínima de vivienda (soportada por las políticas habitacionales del gobierno nacional), que beneficia la inversión de capital para las empresas constructoras y no el mejoramiento significativo de la calidad de vida del usuario.
Mientras se sigan produciendo y repitiendo modelos de viviendas unifamiliares y multifamiliares sin combinar con otras alternativas que favorezcan el desarrollo y evolución de estas y su entorno, los espacios urbano-arquitectónicos creados para la VIS no contribuirán a la equidad social y el derecho a la ciudad, así como al adecuado crecimiento y desarrollo urbano.

Unido a lo anterior, y lejos de la lógica de desarrollo de los usuarios, las viviendas no conciben espacios que permitan la adquisición de recursos económicos que favorezcan el sustento familiar como alternativa para lograr una mejor calidad de vida, y en aquellas soluciones donde se incorpora una actividad económica, esta ocurre en detrimento de la funcionalidad y relaciones espaciales de la vivienda.

Por otra parte, incluyendo no solo la actividad profesional de la arquitectura sino también de otras profesiones, la calidad de la vivienda para los sectores de bajos ingresos económicos debe ser enfocada a partir de la visión y experiencia de diferentes disciplinas integradas, razón por la cual en esta investigación desde un inicio se vincularon especialistas en los campos de la economía, el trabajo social y las ciencias básicas. Esta postura multidisciplinaria debe ser aún más amplia, y no solo en el trabajo científico y académico, sino también en la concepción y desarrollo de los proyectos y el seguimiento de los mismos. 
Pero un seguimiento adecuado de los proyectos de vivienda de interés social tampoco ocurre por los promotores o constructores de las soluciones habitacionales, los cuales permitirían retroalimentar las experiencias con vistas a mejorar la calidad en futuras realizaciones y hacer propuestas para cambiar la común estandarización de las viviendas que generan rechazo, resignación y conformidad en los usuarios, lo cual afecta su bienestar y limita su participación en el mejoramiento de la vivienda y su entorno.

Con respecto a la participación de los usuarios en la producción y trasformación de su hábitat, en la muestra no se desarrollan alternativas para el diseño participativo $u$ otras acciones que involucren al beneficiario en la concepción, producción y transformación de las soluciones habitacionales, lo cual genera problemas de convivencia, adaptabilidad y flexibilidad.
Finalmente, la calidad integral del hábitat, además de la participación activa no solo de los profesionales y los usuarios, sino también de la ciudad mediante su ubicación y si la vivienda de interés social en la periferia permite reducir los precios por el bajo valor del suelo urbano, finalmente genera altos costos de movilidad, elevados consumos de energía, depredación del suelo rural y segregación socio-espacial.

Por otra parte, los modelos financieros para el acceso a la vivienda de interés social contradicen el derecho constitucional de adquirir una vivienda propia y digna, ya que no se benefician los sectores más vulnerables que constituyen el estrato 1 , y quien adquiere una vivienda de interés social recibe alternativas rígidas de diseños arquitectónicos, que imposibilitan transformaciones internas y comunitarias en beneficio de la vivienda productiva, la producción industrial a baja escala, la producción artesanal o de servicios. 


\section{Referencias bibliográficas}

ARAVENA, Alejandro. Elemental. Revista 180. (16): 1016, Diciembre 2005. ISSN 0718-2309.

DE LA PUENTE, Patricio, TORRES, Emilio, MUÑOZ, Patricia. Satisfacción residencial en soluciones habitacionales de radicación y erradicación para sectores pobres de Santiago. [En línea]. EURE. 16(49): 7-22, noviembre 1990. ISNN 0717-6236 [Fecha de consulta: 01 abril 2011]. Disponible en: http://www.eure.cl/numero/satisfaccion-residencial-en-soluciones-habitacionales-de-radicaciony-erradicacion-para-sectores-pobres-de-santiago/.

DEPARTAMENTO Administrativo Nacional de Estadística, DANE. Investigación de registro administrativo: Estadísticas de edificación, licencias de construcción [sin publicar]. Septiembre 2007 [Fecha de consulta: 25 octubre 2008]. Disponible en: Departamento de atención al público, DANE.

DEPARTAMENTO Nacional de Planeación, DNP. Evaluación de impacto del programa de vivienda de interés social urbana. [En línea]. Departamento Nacional de Planeación. Septiembre 2007. [Fecha de consulta: 25 febrero 2008]. Disponible en: http://www.dnp.gov.co/PortalWeb/Portals/0/archivos/documentos/DEPP/Evaluaciones_Focalizadas/Instrucctivo_\%20Linea_Base_VISU.pdf

GARCÍA Huidobro, Fernando; TORRES, Diego y TUGAS, Nicolás. PREVI Lima: 35 años después. [En línea]. ARQ. (59): 72-76, 2005 [Fecha de consulta: 03 agosto 2010]. Disponible en:
http://www.scielo.cl/scielo.php?pid=S0717$69962005005900016 \&$ script=sci_arttext

GONZÁLEZ Couret, Dania. Economía y calidad en la vivienda. La Habana, Cuba, Editorial Científico Técnica. 1998. 167 p. ISBN 959-05-0169-9

HIDALG0, Rodrigo y SALDÍAS Rivas, Bruno. La satisfacción residencial de los usuarios en los programas de vivienda social en Santiago de Chile. [En línea]. EN: Congreso de Cealc (3a , 1998, Barcelona, España). III Congreso de Centro de Estudios de América Latina de Cataluña. Barcelona, España, Universidad de Vic (Barcelona). Reproducido en Scripta Vetera, Revista electrónica de trabajos publicados sobre Geografía y Ciencias Sociales. (83). ISSN: 1578-0015. Disponible en: http://www. ub.es/geocrit/sv-83.htm

JIMÉNEZ Claros, Sonia y TERCEROS Rojas, Óscar. Hacia la construcción de políticas sociales inclusivas y prácticas que garanticen un hábitat digno. Seminarios departamentales de políticas sociohabitacionales en Bolivia. Cuaderno de análisis PROMESHA. (18): 3-43, 2009. ISSN 1652-571x.

LEVA, Germán. Indicadores de calidad de vida urbana. Teoría y metodología. [En línea]. Buenos Aires, Argentina, Universidad Nacional de Quilmes. 2005. 100 p. ISBN 45382-4288-2005 Disponible en : http://hm.unq.edu.ar/archivos_hm/ GL_ICVU.pdf

PÉREZ Pérez, Alex Leandro. Diagnostico preliminar de la calidad del hábitat urbano para la vivienda de interés social producida en el periodo 20002007 en Colombia. [En línea]. SEMINARIO Na-

revista invi № 72 / Agosto 2011 / Volumen N² 26: 95-126 125 
cional de Investigación Urbano-Regional ACIUR. (7 $7^{\mathrm{a}}$, 2008, Medellín, Colombia). VII Seminario Nacional de Investigación Urbano-Regional ACIUR: diversidad y desigualdad en los territorios contemporáneos. Medellín, Colombia, Universidad Nacional de Colombia. 2008. Disponible en: http://www.institutodeestudiosurbanos.com/ index.php?option=com_docman\&task=doc_ details\&gid=201\&Itemid $=18$

PNUD, Programa de Naciones Unidas para el Desarrollo Humano. Informes regionales, nacionales y subnacionales sobre Desarrollo Humano. [En línea]. PNUD. 2000-2009 [Fecha de consulta: 6 junio 2008]. Disponible en: http://hdr.undp.org/ es/informes/indh/

SALDARRIAGA Roa, Alberto. Habitabilidad y calidad de la vivienda: una mirada necesaria. En: Calidad de la vivienda dirigida a los sectores de bajos ingresos en Bogotá. Bogotá, Colombia, Centro Editorial Javeriano. 2003. p. 18-19 ISBN 958-683-546-4
SUBSECRETARÍA de Planeación Socioeconómica, Alcaldía Mayor de Bogotá D.C, Departamento Administrativo Nacional de Estadística, DANE. Encuesta de Calidad de Vida Bogotá 2007. [En línea]. Secretaría de Planeación. 2008. [Fecha de consulta: 2 julio 2008]. Disponible en: http://www.sdp.gov. co/resources/calidad_de_vida_07.pdf

\section{TARCHÓPULOS Sierra, Doris y CEBALLOS Ramos, Olga}

Lucia. Calidad de la vivienda dirigida a los sectores de bajos ingresos en Bogotá. Bogotá, Colombia, Centro Editorial Javeriano. 2003. 100 p. ISBN 958-683-546-4.

UNIVERSIDAD de La Salle. Diagnóstico preliminar de la calidad del hábitat en proyectos VIS (20002007) en Colombia, hacia un manifiesto nacional de calidad del hábitat. (Colectivo de investigación y asesores, documento final, resultados de investigación). Bogotá, Colombia, Universidad de La Salle. 2009. 250 p. (sin publicar). 